\title{
TRANSGENIC SWINE LUNGS EXPRESSING HUMAN CD59 ARE PROTECTED FROM INJURY IN A PIG-TO-HUMAN MODEL OF XENOTRANSPLANTATION
}

David M. Kulick, MD

Christopher T. Salerno, MD

Agustin P. Dalmasso, MD ${ }^{\mathrm{b}, \mathrm{c}}$

Soon J. Park, MD

Manuel Guzman Paz, MD

William L. Fodor, $\mathrm{PhD}^{\mathrm{d}}$

R. Morton Bolman III, MD
Background: Pulmonary xenotransplantation is currently limited by hyperacute rejection mediated in part by xenoreactive natural antibody and complement. Transgenic swine organs that express the human complement regulatory protein CD59 have demonstrated improved survival in models of pig-to-primate xenotransplantation.

Objective: The purpose of this study was to evaluate transgenic swine lungs that express the human complement regulatory protein CD59 in a model of pig-to-human xenotransplantation.

Methods: Transgenic swine lungs ( $\mathrm{n}=5$, experimental group) and outbred swine lungs ( $n=6$, control group) were perfused with fresh, whole human blood through a centrifugal pump on an ex vivo circuit. Functional data were collected throughout perfusion. Immunoglobulin and complement studies were performed on perfusate samples, and both histologic and immunofluorescent analyses were performed on tissue sections.

Results: Mean lung survival for the experimental group was increased when compared with controls, $240 \pm 0$ minutes versus $35.3 \pm 14.5$ minutes, respectively, with a $P$ value of less than .01 . A decreased rise in pulmonary vascular resistance at 15 minutes was observed in the experimental group (343 \pm $87 \mathrm{~mm} \mathrm{Hg} \cdot \mathrm{L}^{-1} \cdot \mathrm{min}^{-1}$, in contrast to the control group $(1579 \pm 722 \mathrm{~mm} \mathrm{Hg}$ $\left.\cdot \mathrm{L}^{-1} \cdot \mathrm{min}^{-1} ; P<.01\right)$. Pulmonary compliance at 15 minutes was improved for the experimental group versus control group $\left(9.31 \pm 1.41 \mathrm{~mL} \cdot \mathrm{cm}^{-2} \mathrm{H}_{2} \mathrm{O}\right.$ and $4.11 \pm 2.84 \mathrm{~mL} \cdot \mathrm{cm}^{-2} \mathrm{H}_{2} \mathrm{O}$, respectively; $\left.P<.01\right)$. SC5b-9 generation in the plasma perfusate was delayed for the experimental group versus the control group. Immunofluorescent examination of tissue sections demonstrated equivalent deposition of immunoglobulin $\mathrm{G}$, immunoglobulin $\mathrm{M}, \mathrm{C} 1 \mathrm{q}$, and C3 in both groups, with reduced deposition of C9 in the experimental group.

Conclusions: Transgenic swine pulmonary xenografts that express the human complement regulatory protein CD59 demonstrated improved function and survival in an ex vivo model of pig-to-human xenotransplantation. ( $\mathrm{J}$ Thorac Cardiovasc Surg 2000;119:690-9)
From the Departments of Surgery ${ }^{\mathrm{a}}$ and Laboratory Medicine and Pathology, ${ }^{\mathrm{b}}$ University of Minnesota, Minneapolis, the Veterans Affairs Medical Center, ${ }^{c}$ Minneapolis, Minn, and Alexion Pharmaceuticals, ${ }^{\mathrm{d}}$ New Haven, Conn.

Supported by the US Department of Commerce, National Institute of Standards and Technology/Advanced Technology Program Cooperative Agreement, DVA Medical Research, and the Minnesota Medical Foundation.

R.M.B. holds the C. Walton and Richard C. Lillehei Endowed Chair in Cardiovascular and Thoracic Surgery.

Read at the Seventy-ninth Annual Meeting of The American Association for Thoracic Surgery, New Orleans, La, April 18-21, 1999.

Received for publication June 3, 1999; revisions requested Sept 15, 1999; revisions received Oct 28, 1999; accepted for publication Nov 1, 1999.

Address for reprints: David M. Kulick, MD, University of Minnesota, Department of Surgery, UMHC Box 1, 420 Delaware St SE, Minneapolis, MN 55455 (E-mail: kuli0004@tc.umn.edu).

12/6/104159

doi:10.1067/mtc.2000.104159 ung transplantation is recognized as the best current therapy for patients with end-stage pulmonary failure. The organ shortage for lung transplantation is more severe than for any other solid organ. Currently, more than 3200 patients are awaiting lung transplantation in the United States; in 1998, 486 people died waiting for a lung transplant. ${ }^{1}$ Despite the aggressive efforts being made to increase the donor pool, it is unlikely that human donors will ever meet the expanding organ demand. Because mechanical lung replacement devices have not had a significant clinical impact, animal donors are being considered as a potential source of organs. Because there are many limitations to the use of nonhuman primate donors, currently the pig is being proposed as the most suitable organ donor for human xenotransplantation. A major obstacle to successful 
pig-to-primate xenotransplantation is hyperacute rejection. ${ }^{2}$ Hyperacute rejection results from the binding of xenoreactive antibodies to donor endothelium with subsequent activation of complement, which leads to the loss of endothelial cell integrity, tissue edema, thrombosis, and loss of graft function. ${ }^{3}$ Because complement membrane-associated regulatory proteins are relatively species specific, the transgenic engineering of swine to express human regulatory proteins is a potentially viable method of preventing the progression of hyperacute rejection in swine organs that are exposed to primate complement. ${ }^{4,5}$ The complement regulatory protein CD59 prevents the complete assembly of the membrane attack complex of complement by blocking the binding of $\mathrm{C} 9$ to $\mathrm{C} 5 \mathrm{~b}-8$ and inhibiting the polymerization of C9. ${ }^{5}$ Expression of human CD59 (hCD59) on the surface of porcine aortic endothelial cells confers protection against primate complementmediated cytotoxicity in vitro, and ex vivo perfusion with human blood of swine hearts and kidneys transgenic for hCD59 demonstrated prolonged survival over nontransgenic controls. ${ }^{6}$

Individual organ characteristics define physiologic mechanisms through which hyperacute rejection and resulting organ failure may be manifested. Hyperacute rejection of the lung occurs in a way that makes it unique compared with other solid organs, such as the heart or the kidney. In the lung during hyperacute rejection, there occurs a precipitous rise in pulmonary vascular resistance (PVR), which markedly reduces organ perfusion and impairs respiratory function. Canine and porcine lungs that were exposed to human blood for evaluation as potential extracorporeal oxygenators revealed a significant reduction in forward pulmonary perfusive blood flow. ${ }^{7,8}$ Models of pig-to-human cardiopulmonary and isolated pulmonary xenotransplantation have shown that this elevation in PVR is manifested when hyperacute rejection occurs in these combinations. ${ }^{9-12}$ However, one experiment that studied pig-to-primate lung transplantation in vivo suggested that the lung was protected from hyperacute rejection. ${ }^{13}$

Strategies designed to reduce the contribution of complement to hyperacute rejection in a pig-to-primate combination have demonstrated the potential for improved function and survival for pulmonary xenografts. Transgenic expression of both human decay accelerating factor (hDAF) and hCD59 in swine lungs had a protective effect in an ex vivo human plasma perfusion model, which was demonstrated by better perfusion and reduced pulmonary edema in the transgenic organs as compared with unmodified controls. ${ }^{14}$ Subsequent in vivo pig-to-primate transplantations with transgenic swine lungs that expressed hCD59 and
hDAF, with or without the administration of cobra venom factor to the recipient, supported previous results obtained with the ex vivo plasma perfusion model; however, these studies did not demonstrate a protective effect of cobra venom factor alone in this combination. ${ }^{15}$ Studies of transgenic lungs that express $\mathrm{hDAF}$ in an ex vivo whole-blood perfusion model of pig-to-human xenotransplantation demonstrated improved function and survival of organs with high levels of $\mathrm{hDAF}$ expression. ${ }^{16}$

In the present study, we examined pig-to-primate lung xenotransplantation in a whole blood perfusion ex vivo model to identify events associated with rejection of a discordant pulmonary xenograft and to elucidate the potential protective effect of the transgenically expressed isolated hCD59 on a swine lung.

\section{Material and methods}

Animals. Outbred Yorkshire swine (Midwest Research Swine, Gibbon, Minn) that weighed 20 to $30 \mathrm{~kg}$ served as control lung donors. Transgenically engineered swine that expressed hCD59 (20-30 kg) were supplied by Alexion Pharmaceuticals Incorporated (New Haven, Conn). They were derived from founder animals that were generated by directionally cloning an hCD59 complement DNA into exon 1 of the murine $\mathrm{H} 2 \mathrm{~K}^{\mathrm{b}}$ gene ${ }^{4}$; the purified $\mathrm{H}_{2} \mathrm{~K}^{\mathrm{b}}$ hCD59 DNA was then injected into porcine embryos. Use of the murine major histocompatibility class I gene $\mathrm{H} 2 \mathrm{~K}^{\mathrm{b}}$ provided near ubiquitous expression of the hCD59 on most somatic cells and, most important, on endothelial cell surfaces. ${ }^{4}$ Transgenic swine heterozygous for the hCD59 transgene were screened with the use of slot blot analysis of tail vein resections as previously described ${ }^{6}$ before delivery to our facility. All animals received humane care in compliance with the "Principles of Laboratory Animal Care" formulated by the Institute of Laboratory Animal Resources and the "Guide for the Care and Use of Laboratory Animals" formulated by the National Institutes of Health (NIH Publication No. 86-23, revised 1985).

Donor operation. After the induction of anesthesia with ketamine $(16 \mathrm{mg} / \mathrm{kg})$, tiletamine (Telazol; $4 \mathrm{mg} / \mathrm{kg}$ ), and thiopental sodium (Pentothal; $12 \mathrm{mg} / \mathrm{kg}$ ), the animals were endotracheally intubated and placed on a mechanical ventilator with inhalational isoflurane (1.5-2 vol\%) for maintenance anesthesia. The animals' lungs were ventilated with a tidal volume of $10 \mathrm{~cm}^{3} / \mathrm{kg}$ and an inspired oxygen concentration of $100 \%$. After a median sternotomy was performed, the pericardium was opened; the inferior vena cava was encircled twice with umbilical tapes, and the superior vena cava was encircled inferior to the entrance of the azygous and hemiazygos systems. The donor animal was then systemically heparinized (165 units/kg intravenously), and the inferior pulmonary ligaments were sharply divided. A euthanizing dose of thiopental sodium was administered, and the trachea was clamped at peak inspiration before division of the venae cavae and procurement of the heart-lung block. The left lung 
was dissected free from the heart-lung block, and all bronchi and blood vessels that served other portions of the heart-lung block were ligated.

Ex vivo lung perfusion model. The lung was instrumented by an endotracheal tube in the left main stem bronchus and an arterial cannula in the left main pulmonary artery. All donor lungs were then flushed with up to $500 \mathrm{~mL}$ of room temperature saline solution until the effluent from the pulmonary veins was clear. An arterial pressure catheter was placed in line with the pulmonary arterial cannula. The lung was then placed horizontally in a plastic reservoir. The venous return drained passively through the pulmonary veins and was collected in a 3000-mL cardiotomy reservoir equipped with a 20- $\mu \mathrm{m}$ filter (Medtronic, Anaheim, Calif). Blood was circulated with a Bio-Medicus centrifugal pump (Medtronic Bio-Medicus, Eden Prairie, Minn), passed through a hollow-fiber deoxygenator, and returned to the lung through the pulmonary artery. A 95\% nitrogen/5\% carbon dioxide gas mixture was administered to the deoxygenator (Medtronic). Perfusate temperature was maintained at $37^{\circ} \mathrm{C}$ through the use of a warm water circulator attached to the deoxygenator. The lung was ventilated with heated, humidified gas with an inspired oxygen fraction of 50\%, delivered by a ventilator (Siemens 900B; Siemens-Elema, Solna, Sweden) with physiologic peak end-expiratory pressure (PEEP), a respiratory rate of 12 , and a tidal volume to maintain peak airway pressure below $35 \mathrm{~cm} \mathrm{H}_{2} \mathrm{O}$. Total ischemic time was consistently less than 20 minutes from the time of heart-lung block harvest to the time of ex vivo perfusion. All lung preparations were perfused with fresh human blood that was obtained from healthy donors and used within 3 hours of donation. The use of human subjects as blood donors was in accord with the University of Minnesota Committee on the Use of Human Subjects in Research. Each perfusion experiment was performed with 1 unit of fresh blood $(450 \mathrm{~mL})$ that was anticoagulated with 2.2 units heparin per milliliter, and $150 \mathrm{~mL}$ of crystalloid was added to give an operational total circuit volume of $600 \mathrm{~mL}$. Normal human blood donor types used to perfuse the control group included 4 A-positive donors and 2 O-positive donors. Perfusion of the transgenic lungs was performed with blood from 3 A-positive donors and 2 O-positive donors. All blood donors were screened and selected on the basis of normal levels of xenoreactive natural antibody, and those who had a level higher than the mean of the group minus 2 standard deviations were used so that no organ perfusion study was compromised by low xenoreactive immunoglobulin (Ig) M or G levels. ${ }^{6}$

Blood samples were obtained at defined time intervals for the measurement of antibody, complement, and complete blood counts including hemoglobin, platelets, and leukocytes. The hemoglobin level of the perfusate was 10 to 12 $\mathrm{g} / \mathrm{dL}$ at the beginning of each ex vivo perfusion and was consistently above $7 \mathrm{~g} / \mathrm{dL}$ by the completion of the perfusion. Perfusion circuits were primed and circulated before perfusion was initiated. Electrolyte and $\mathrm{pH}$ adjustments were made before organ perfusion. Glucose, free water, and electrolytes were added as needed during the experiment. The end point for each perfusion experiment was determined by the inability to oxygenate the perfusate defined as an arteriovenous oxygen difference $\left(\Delta \mathrm{AVO}_{2}\right)$ less than $10 \mathrm{~mm} \mathrm{Hg}$ determined by serial blood gas analyses, the inability to maintain forward perfusive pulmonary blood flow of $1 \mathrm{~mL} / \mathrm{gm}$ tissue per minute at a mean pulmonary perfusion pressure of no greater than $30 \mathrm{~mm} \mathrm{Hg}$, or an increase in the peak airway pressure of more than $40 \mathrm{~mm} \mathrm{Hg}$, with resulting bleb rupture; if none of these criteria occurred by 240 minutes or more, the experiment was electively terminated.

Functional measurements. In each experiment, pulmonary artery pressure, pulmonary artery flow, peak airway pressure, tidal volume, and venous and arterial blood gases were monitored. From these measurements the PVR, pulmonary compliance, $\Delta \mathrm{AVO}_{2}$, and alveolar-arterial oxygen gradient (A-a $\mathrm{O}_{2}$ gradient) were calculated. Venous samples were taken from blood exiting the deoxygenator, and arterial samples were taken directly from the pulmonary venous effluent. Blood $\mathrm{pH}$ adjustments were made as necessary to maintain an arterial $\mathrm{pH}$ of 7.4.

PVR was calculated from the measurements of blood flow with a Bio-Medicus flow probe (Medtronic Bio-Medicus) and mean pulmonary artery pressure with the use of the following equation:

PVR $\left(\mathrm{mm} \mathrm{Hg} \cdot \mathrm{L}^{-1} \cdot \mathrm{min}^{-1}\right)=$ mean pulmonary artery pressure $(\mathrm{mm} \mathrm{Hg}) /$ blood flow $(\mathrm{L} / \mathrm{min})$

Pulmonary compliance was calculated from the measured tidal volume and peak airway pressure with the use of the following equation:

Pulmonary compliance $\left(\mathrm{mL} \cdot \mathrm{cm}^{-2} \mathrm{H}_{2} \mathrm{O}\right)=$ tidal volume $(\mathrm{mL}) /$ peak airway pressure $\left(\mathrm{cm}^{2} \mathrm{H}_{2} \mathrm{O}\right)-\operatorname{PEEP}\left(\mathrm{cm}^{2} \mathrm{H}_{2} \mathrm{O}\right)$

where PEEP is positive end-expiratory pressure.

Change in arteriovenous oxygen $\left(\Delta \mathrm{AVO}_{2}\right)$ was calculated from the formula:

$$
\begin{gathered}
\Delta \mathrm{AVO}_{2}(\mathrm{~mL} \text { oxygen } / 100 \mathrm{~mL} \text { blood })=\mathrm{PaO}_{2} \cdot 0.0031+ \\
\left([1.34 \cdot \text { hemoglobin }] \cdot\left[\mathrm{S}_{\text {art }} \cdot 10^{3}\right]\right)-\mathrm{PvO}_{2} \cdot 0.0031+ \\
\left([1.34 \cdot \text { hemoglobin }] \cdot\left[\mathrm{S}_{\text {ven }} \cdot 10^{3}\right]\right)
\end{gathered}
$$

Where $\mathrm{S}_{\text {art }}$ is arterial saturation, and $\mathrm{S}_{\mathrm{ven}}$ is oxygen saturation; where $\mathrm{PaO}_{2}$ is arterial partial pressure of oxygen, and $\mathrm{PvO}_{2}$ is venous partial pressure of oxygen in millimeters of mercury in the venous effluent; and hemoglobin concentration is in grams per deciliter.

The A-a $\mathrm{O}_{2}$ gradient was calculated from the formula:

A-a $\mathrm{O}_{2}$ gradient $(\mathrm{mm} \mathrm{Hg})=\left(\left[\mathrm{FIO}_{2} \cdot 713\right]-\mathrm{PaCO}_{2}\right)-\mathrm{PaO}_{2}$

Where $\mathrm{FIO}_{2}$ is the fractional inspired oxygen concentration, $\mathrm{PaCO}_{2}$ is the partial pressure of carbon dioxide in millimeters of mercury in the venous effluent, and $\mathrm{PaO}_{2}$ is the partial pressure of oxygen in millimeters of mercury in the venous effluent.

Xenoreactive natural IgG and IgM antibody levels. Xenoreactive natural $\operatorname{IgG}$ and $\operatorname{IgM}$ antibody levels were determined with the use of an enzyme-linked immunosorbent assay. ${ }^{17}$ Swine aortic endothelial cells were harvested and cultured in 96-well plates. Monolayers were fixed with $0.1 \%$ 
glutaraldehyde in HBSS-25 mmol/L HEPES, pH 7.4 (Gibco, Grand Island, NY) and washed. One percent bovine serum albumin was added to block nonspecific binding sites. Serial dilutions of human serum samples were added to the wells, which was followed by sequential washing. Alkaline phosphatase-conjugated goat anti-human IgG or IgM was added to each well, and the plates were incubated for 60 minutes at $37^{\circ} \mathrm{C}$ for IgG and $4^{\circ} \mathrm{C}$ for IgM. The reaction was developed with a solution containing $0.5 \mathrm{mmol} / \mathrm{L} \mathrm{MgCl}_{2}, 1 \mathrm{mg} / \mathrm{mL}$ nitrophenylphosphate, and $100 \mathrm{mmol} / \mathrm{L}$ diethanolamine, $\mathrm{pH}$ 9.5. Well absorbance was determined at $405 \mathrm{~nm}$ with a plate reader (Vmax Kinetic reader; Molecular Devices, Sunnyvale, Calif). For negative controls, wells were prepared as described earlier without the addition of human serum. Statistically significant binding $(P<.05)$ was determined if absorbance of individual samples was in excess of 2 standard deviations above the mean binding of negative controls. A pool of normal human blood donors was used at a 1:2 dilution, and the absorbance at $405 \mathrm{~nm}$ was assigned an arbitrary value of 100. Absorbance at $405 \mathrm{~nm}$ from experimental samples at a $1: 2$ dilution was compared with this pool and expressed as a fractional percentage of the pooled value of 100 . Total IgG and IgM levels were measured by nephelometry.

Complement assays. For the fluid phase measurements of C3a and SC5b-9, blood samples were drawn in ethylenediaminetetraacetic acid tubes at scheduled time points from the ex vivo perfusion circuit, and the plasma was separated and frozen immediately at $-80^{\circ} \mathrm{C}$. C3a as the $\mathrm{C} 3 \mathrm{a}$ des-arg product and SC5b-9 were measured in freshly thawed serum samples by enzyme-linked immunosorbent assay (Quidel Corp, San Diego, Calif). Measurement of hemolytic complement activity of the classic pathway (50\% hemolyzing dose of complement $\left[\mathrm{CH}_{50}\right]$ ) was performed in 96-well flat-bottomed microtiter plates. Sequential blood samples were collected from each perfusion experiment and centrifuged for $20 \mathrm{~min}$ utes at $2000 \mathrm{~g}$ at $4^{\circ} \mathrm{C}$; the serum was pipetted off, aliquoted, and frozen at $-80^{\circ} \mathrm{C}$. Serum samples were thawed and serially diluted with buffer consisting of $5 \mathrm{mmol} / \mathrm{L} \mathrm{Na}$ Veronal, 145 $\mathrm{mmol} / \mathrm{L} \mathrm{KCl}, 0.15 \mathrm{mmol} / \mathrm{L} \mathrm{CaCl}{ }_{2}$, and $1 \mathrm{mmol} / \mathrm{L} \mathrm{MgCl}_{2}$, containing $0.5 \%$ human serum albumin (Veronal buffer). To each well in the microtiter plate, $50 \mu \mathrm{L}$ of diluted serum was mixed with $50 \mu \mathrm{L}$ of sensitized sheep red blood cells at $10^{8} / \mathrm{mL}$ in Veronal buffer. ${ }^{18}$ The plates were then incubated at $37^{\circ} \mathrm{C}$; mixing occurred after $150 \mu \mathrm{L}$ of Veronal buffer was added, for a total of $250 \mu \mathrm{L}$ per well. Absorbance at $650 \mathrm{~nm}$ was measured with a Vmax kinetic microplate reader. ${ }^{19} \mathrm{CH}_{50}$ was expressed as the reciprocal of the serum dilution, yielding a $50 \%$ reduction in turbidity.

Histology and immunofluorescence. Lung parenchyma and pulmonary vasculature tissue sections were obtained at the completion of each experiment. Tissue specimens were formalin fixed, embedded in paraffin, sectioned, stained with hematoxylin and eosin, and examined by light microscopy. Additional tissue samples were embedded in OCT compound (Sakura Finetek USA Inc, Torrance, Calif) and snap-frozen in prechilled isopentane and liquid nitrogen and stored at $-80^{\circ} \mathrm{C}$. Tissue specimens were sectioned to $4-\mu \mathrm{m}$ thickness on a Lipshaw cryostat (Cryotome, Detroit, Mich), air dried, acetone fixed, and washed with phosphate-buffered saline solution ( $\mathrm{pH}$ 7.35-7.45). Fluorescein isothiocyanate (FITC)conjugated antibodies were preabsorbed with pig serum for 12 hours to inhibit nonspecific binding, centrifuged for 10 minutes at $10,000 \mathrm{~g}$, and separated into aliquots to be stored at $-70^{\circ} \mathrm{C}$ until needed. The sections were stained with FITCconjugated antibodies specific for human IgM, C1q, C3, C4, properdin, fibrinogen (Diasorin Inc, Stillwater, Minn), and IgG (Sigma Chemical Company, St Louis, Mo). In addition, tissues were stained with a murine anti-human monoclonal antibody specific for $\mathrm{C} 9$ neoantigen, ${ }^{20}$ followed by a fluorescein-labeled goat anti-murine monoclonal antibody (Organon Teknika Corp, Durham, NC). Tissues were also stained with a murine anti-hCD59 monoclonal antibody (Biodesign International, Kennebunk, Maine) followed by an FITC-conjugated goat anti-murine IgG (Organon Teknika Corp). Sections were viewed on a Zeiss epifluorescence microscope (Carl Zeiss, Inc, Thornwood, NY) and photographed.

Statistical analysis. Data are reported as mean \pm SD. Analysis of data was performed using a 2-way analysis of variance on a commercially available computer statistics package to determine significance (SPSS Incorporated, Chicago, Ill).

\section{Results}

Survival time and weight increase of porcine lungs perfused with human blood. Swine lungs that expressed hCD59 had prolonged survival versus the controls $(240 \pm 0$ minutes vs $35.3 \pm 14.5$ minutes, respectively; $P<.001$ ). Control lung survival was limited by the failure of forward perfusate flow and the loss of lung compliance. All transgenic lungs were functional at the time of perfusion and were electively terminated (240 minutes). Gross appearance of the control lungs included petechial hemorrhages on the visceral pleural surface, a progressive consolidation of the graft with decreased expiratory recoil, and frothy, blood-tinged endotracheal tube secretions. The transgenic lungs remained soft and compliant throughout the perfusion, and the surface of the lung appeared less ecchymotic when compared with controls. Comparison of weight gain as a function of retained perfusate for grafts before and after perfusion did not reveal a significant difference between control and transgenic lungs. Control lungs demonstrated a more rapid and quantitatively higher weight gain than transgenics. Baseline weights for controls were $160.3 \pm 37 \mathrm{~g}$ and $171.9 \pm 25 \mathrm{~g}$ for transgenics $(t$ test: $P=.57$ ). Percentage weight gain at the end of perfusion experiments was $78.9 \% \pm 62 \%$ for controls and $57 \% \pm 32 \%$ for transgenics ( $t$ test: $P=.24$ ).

Functional variables. Control lungs demonstrated a rapid and prolonged rise in PVR in contrast to trans- 


\section{Pulmonary Vascular Resistance}

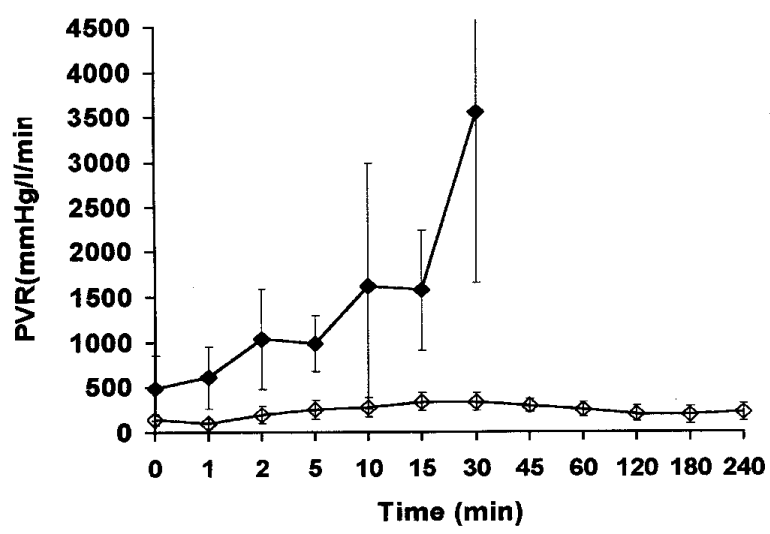

Pulmonary compliance

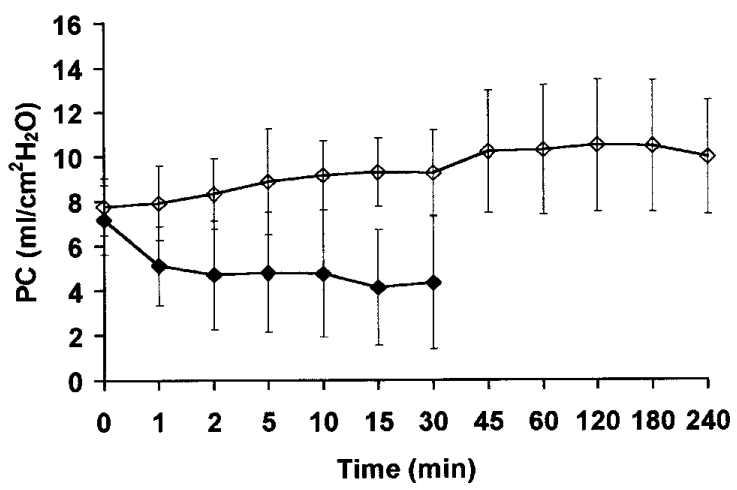

Fig 1. PVR and pulmonary compliance for control $(\diamond)$ and transgenic $(\diamond)$ lungs perfused with human blood (mean \pm standard deviation; $P=.018$ for PVR; $P=.001$ for pulmonary compliance transgenic vs control; analysis of variance). Time 0 represents measurements obtained during the first $15 \mathrm{sec}-$ onds of the experiment. In this and subsequent illustrations, $\mathrm{n}$ $=6$ for the control group and $n=5$ for the transgenic group.

genic lungs (Fig 1). At 30 minutes, PVR was $3558 \pm$ $1902 \mathrm{~mm} \mathrm{Hg} \cdot \mathrm{L}^{-1} \cdot \mathrm{min}^{-1}$ for controls and $341 \pm 89$ $\mathrm{mm} \mathrm{Hg} \cdot \mathrm{L}^{-1} \cdot \mathrm{min}^{-1}$ for transgenics. Pulmonary compliance was improved for transgenic lungs when compared with controls (Fig 1). At 30 minutes, pulmonary compliance was $4.3 \pm 2.9 \mathrm{~mL} \cdot \mathrm{cm}^{-2} \mathrm{H}_{2} \mathrm{O}$ for controls and $9.2 \pm 1.7 \mathrm{~mL} \cdot \mathrm{cm}^{-2} \mathrm{H}_{2} \mathrm{O}$ for transgenics. $\Delta \mathrm{AVO}_{2}$ and $\mathrm{A}-\mathrm{a} \mathrm{O}_{2}$ gradient were similar in both groups (Fig 2).

Xenoreactive natural antibody levels. All levels were corrected for dilution with the use of hematocrit values obtained throughout perfusion with the use of the following formula: $\mathrm{aIg}=\mathrm{mIg} \cdot\left(\mathrm{H}_{0}-\mathrm{H}_{1} / \mathrm{H}_{0}\right.$ where aIg is the adjusted immunoglobulin level, $\mathrm{mIg}$ is the
Arterial-Venous Oxygen Difference

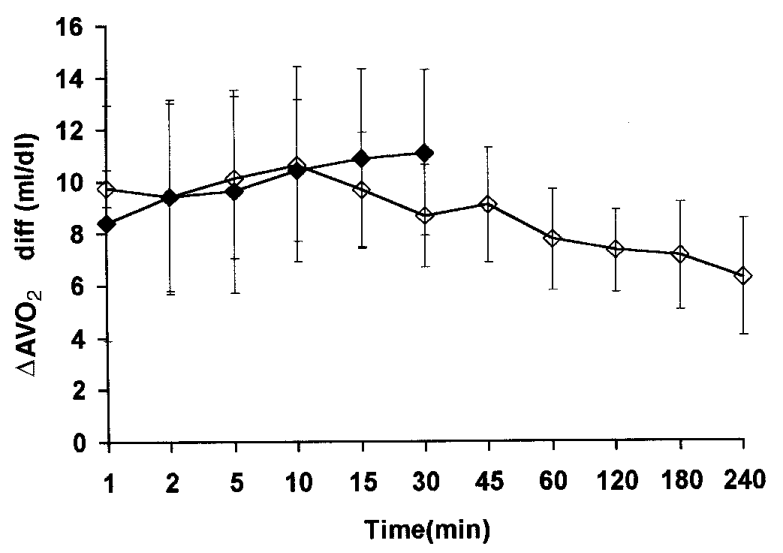

Alveolar-arterial oxygen gradient

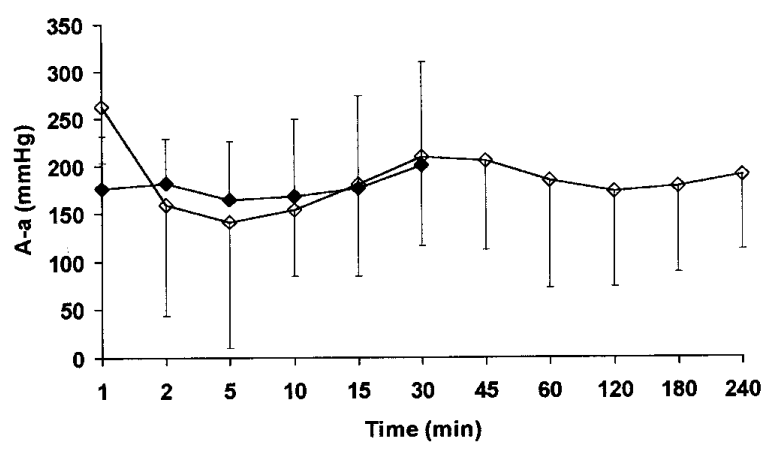

Fig 2. $\Delta \mathrm{AVO}_{2}$ and $\mathrm{A}$-a $\mathrm{O}_{2}$ gradient for control $(\diamond)$ and transgenic $(\diamond)$ lungs perfused with human blood (mean \pm standard deviation).

measured immunoglobulin level, $\mathrm{H}_{0}$ is the hematocrit at the start of the perfusion, and $\mathrm{H}_{1}$ is the hematocrit at the point at which a sample was obtained for the measured immunoglobulin level. Levels were measured at baseline after circuit prime and at specified times during the perfusion experiment. Levels of anti-pig endothelial cell IgG and IgM antibodies decreased similarly in both groups (Fig 3). Before perfusion, xenoreactive $\operatorname{IgG}$ levels were $0.78 \pm 0.24$ units for controls and $0.82 \pm 0.25$ units for transgenics. After 30 minutes of perfusion, there was a $47.6 \% \pm 25.9 \%$ reduction in xenoreactive $\mathrm{IgG}$ levels for controls and a $44.3 \% \pm$ $30.4 \%$ reduction for transgenics. Before perfusion, xenoreactive IgM levels were $1.13 \pm 0.12$ units for controls and $1.11 \pm 0.2$ units for transgenics. After 30 minutes of perfusion, there was a $41.2 \% \pm 4.7 \%$ decrease in xenoreactive IgM levels for controls and a $44.9 \% \pm$ $13.9 \%$ reduction for transgenics. In contrast to the significant decrease in xenoreactive natural antibodies, 


\section{Xenoreactive IgG}

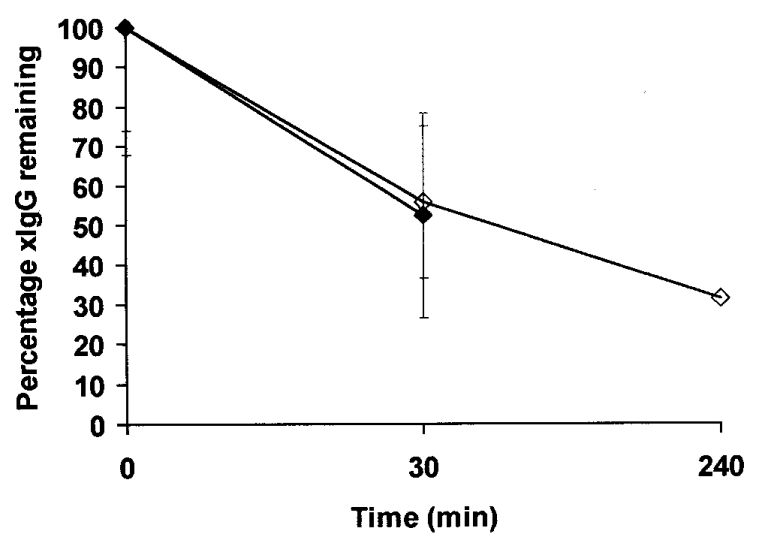

Xenoreactive $\lg M$

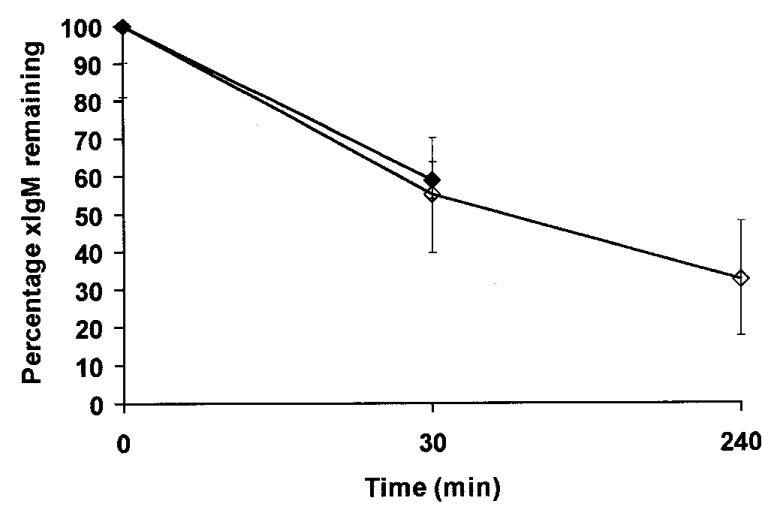

Fig 3. IgG and $\operatorname{IgM}$ xenoreactive natural antibody from control $(\diamond)$ and transgenic $(\diamond)$ lungs perfused with human blood. Levels are expressed as a percentage of values before perfusion. Data are reported as mean \pm standard deviation.

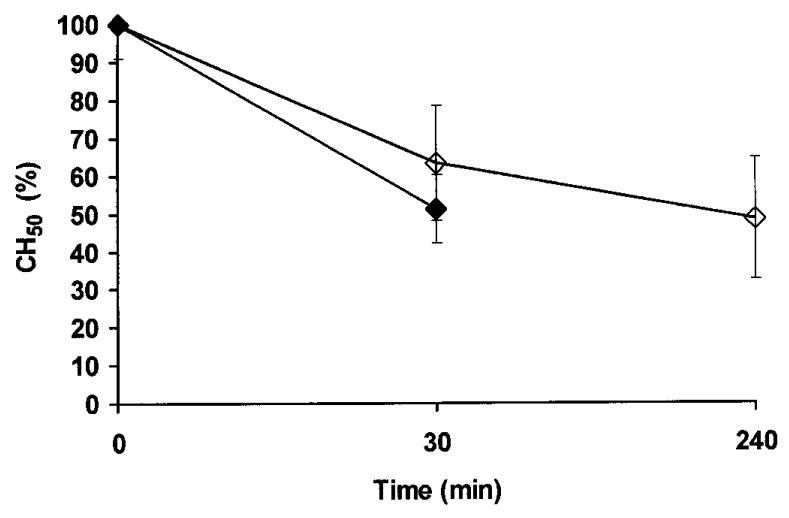

Fig 4. Plasma levels of total complement hemolytic activity $\left(\mathrm{CH}_{50}\right)$ in control $(\diamond)$ and transgenic $(\diamond)$ lungs perfused with human blood. Data are reported as mean \pm standard deviation for percentage decline in $\mathrm{CH}_{50}$ compared with preperfusion levels.

\section{C3a levels}

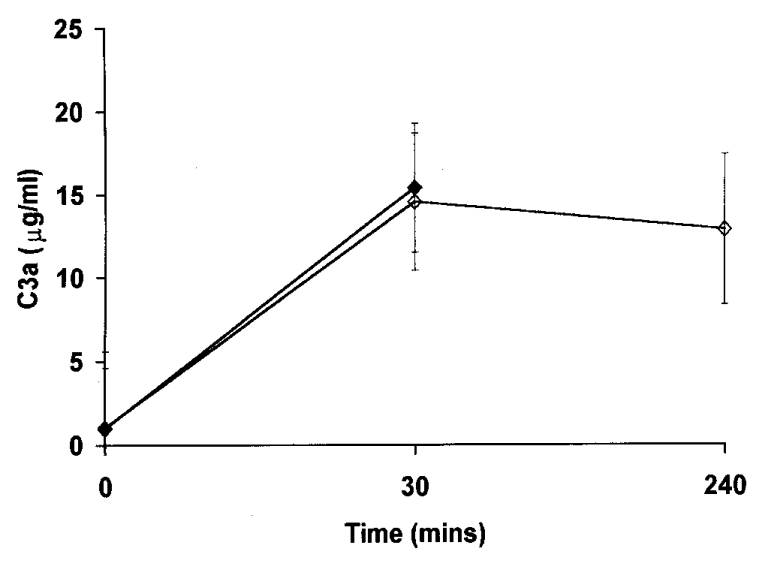

SC5b9 levels

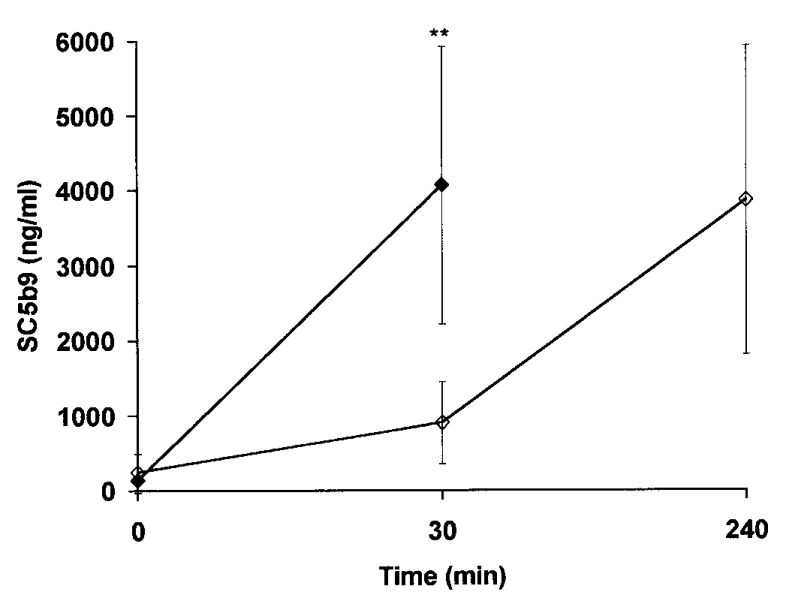

Fig 5. Plasma levels of complement fragment $\mathrm{C} 3 \mathrm{a}$ and soluble complement complex SC5b9 from control ( $\diamond)$ and transgenic $(\diamond)$ lungs perfused with human blood. Data are reported as mean \pm standard deviation $\left({ }^{* *} P<.01, t\right.$ test $)$.

levels of total IgG and IgM decreased only slightly during perfusion in both groups (results not shown).

Hemolytic complement $\left(\mathrm{CH}_{50}\right)$ activity and complement activation assays. Before perfusion, plasma $\mathrm{CH}_{50}$ was $75.8 \pm 25.2$ units for the controls and 75.3 \pm 26.2 units for the transgenics. After 30 minutes of perfusion, $\mathrm{CH}_{50}$ was reduced by $48.7 \% \pm 8.7 \%$ for controls and $36.4 \% \pm 13.9 \%$ for transgenics (Fig 4). In all studies, levels of C3a and SC5b9 increased throughout the experiment; however, there was delayed elevation of SC5b9 levels in the perfused transgenic lungs as compared with controls. C3a levels before perfusion were $0.958 \pm 0.402 \mathrm{ug} / \mathrm{mL}$ for controls and $1.026 \pm$ $0.416 \mathrm{ug} / \mathrm{mL}$ for transgenics (Fig 5). After 30 minutes of perfusion, C3a levels were $15.41 \pm 3.90 \mu \mathrm{g} / \mathrm{mL}$ for controls and $14.58 \pm 3.78 \mu \mathrm{g} / \mathrm{mL}$ for transgenics. 


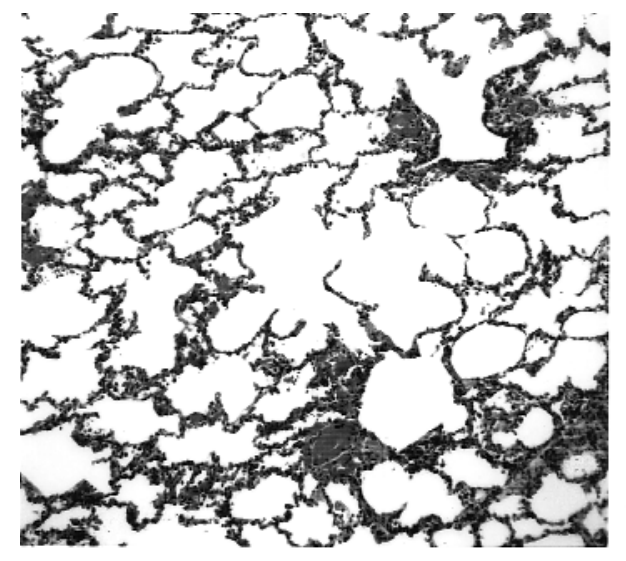

Control

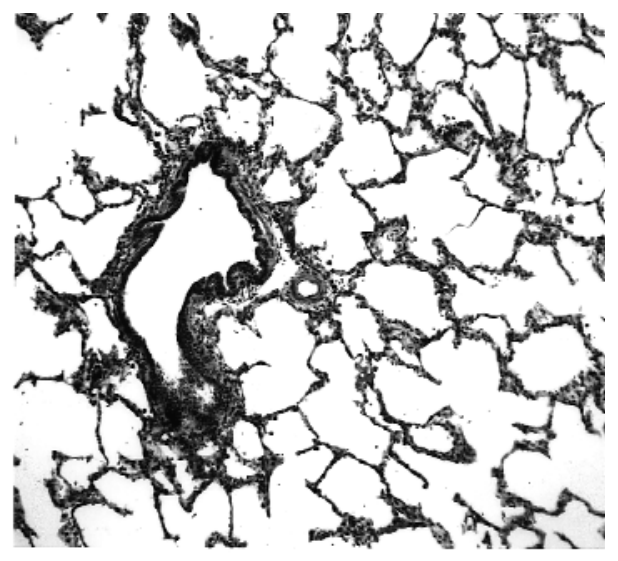

Transgenic

Fig 6. Histologic features of pulmonary parenchymal sections obtained after the completion of the perfusion experiments with human blood (Hematoxylin and eosin stain; original magnification, $\times 40$ ). Control porcine lung tissues reveal interstitial, perivascular, peribronchial hemorrhage, and neutrophil infiltration. Transgenic porcine lung tissues demonstrate reduced interstitial hemorrhage, interalveolar septal edema and congestion, and preserved pulmonary tissue architecture.

$\mathrm{C} 3$

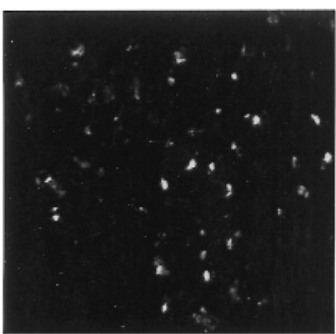

Control

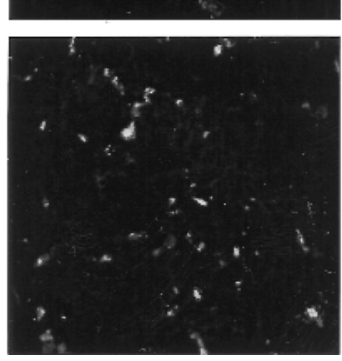

C9
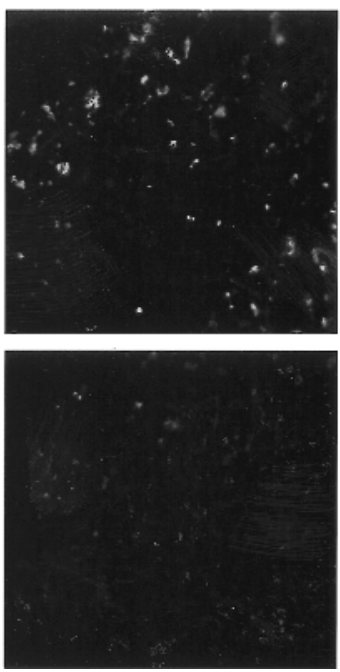

CD59
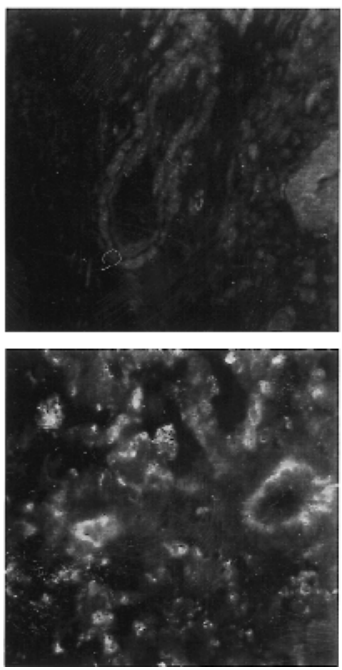

Fig 7. Immunofluorescence analysis of porcine lungs perfused with human blood reveals equivalent deposition of C3 for both control and transgenic lungs. Terminal complement component C9 deposition was reduced in transgenic lungs as compared with control lungs. Preperfusion right porcine lung specimens revealed strong expression of hCD59 in transgenic lung parenchyma and no hCD59 reactivity in control lung parenchyma.

SC5b9 levels before perfusion were $136 \pm 181 \mathrm{ng} / \mathrm{mL}$ for controls and $248 \pm 219 \mathrm{ng} / \mathrm{mL}$ for transgenics. After 30 minutes of perfusion, SC5b9 levels were $4069 \pm$ $1851 \mathrm{ng} / \mathrm{mL}$ for controls and $901 \pm 501 \mathrm{ng} / \mathrm{mL}$ for transgenics $(t$ test: $P<.01)$.
Histopathology and immunofluorescence. Tissues from the control group obtained after perfusion showed characteristic changes consistent with hyperacute rejection, including interstitial and alveolar septal edema, neutrophil infiltration, and some detachment 
of endothelial cells from the basement membrane (Fig 6 ); other findings included microvascular thrombosis and scattered areas of intra-alveolar hemorrhage (data not shown). In contrast, tissues from the transgenic group demonstrated reduced injury. There were interstitial edema, alveolar septal congestion, and neutrophil infiltration, but the endothelial cell layers were preserved in both arterioles and venules (Fig 6). Tissues from all perfusion experiments were studied for the presence of immunoglobulin and complement deposition. Specimens obtained after completion of perfusion from both groups demonstrated similar degrees of deposition of $\mathrm{IgG}, \mathrm{IgM}, \mathrm{C} 1 \mathrm{q}, \mathrm{C} 3, \mathrm{C} 4$, and fibrinogen, as illustrated in Fig 7 for $\mathrm{C} 3$. In lungs from the transgenic group, however, there was marked inhibition of C9 deposition (Fig 7). There was minimal to no deposition of properdin in all specimens from both the control and transgenic groups (data not shown). Tissue samples obtained from the right unperfused lung of the donor swine demonstrated intense staining for hCD59 in the transgenic lung tissues but no staining of hCD59 in the controls (Fig 7).

\section{Discussion}

In the pig-to-primate combination, natural antibodies and complement are known to mediate hyperacute rejection of a cardiac or renal xenograft. ${ }^{21}$ Similar mechanisms have been proposed to explain the immediate rejection of a pig lung transplanted into primates. ${ }^{15,24}$ Both in vivo and ex vivo studies consistently demonstrated a rapid loss of graft function characterized by an increase in PVR, loss of pulmonary compliance, and, over time, an impairment of the oxygenating capabilities of the graft. ${ }^{9-16,22,23}$ In the studies reported here, we used an ex vivo model of pig-to-human lung transplantation and analyzed the injury inflicted by human blood on lungs from normal pigs in comparison with lungs from transgenic donors that express hCD59. We found that perfusion of normal lungs caused a rapid loss of function after a marked increase in PVR and a decrease of lung compliance, similar to previous studies. ${ }^{7,8}$ However, in contrast with previous observations, we detected no reduction in $\Delta \mathrm{AVO}_{2}$, even at the time of organ function loss, and a relatively low degree of edema formation. Several factors may have contributed to maintain these parameters in the face of severely increasing PVR and diminishing compliance. First, in our experiments, we limited the mean pulmonary perfusion pressure to $30 \mathrm{~mm} \mathrm{Hg}$; early in the development of the model we observed that with higher pressures, up to $60 \mathrm{~mm} \mathrm{Hg}$, there was rapid loss of the oxygenating capacity and sequestration of the perfusate within the graft. By reducing the mechanical hemodynamic injury, loss of the ability to perfuse the graft because of the rise in PVR became the limiting factor for graft survival. Second, the use of blood as the perfusate fluid instead of plasma assured improved oxygenation; this may have prevented endothelial cell hypoxia followed by intercellular gap formation and edema $^{14}$ and the consequent loss of oxygenation. Third, we limited the amount of crystalloid solution added to the blood to avoid reducing the colloidosmotic pressure of the perfusion fluid to levels that may promote alveolar transudation and pulmonary edema.

Perfusion of normal lungs and hCD59 lungs with human blood was associated with tissue deposition of $\mathrm{IgM}, \mathrm{IgG}$, and complement components $\mathrm{C} 1, \mathrm{C} 3$, and $\mathrm{C} 4$, marked reduction in anti-pig antibodies and total complement activity from the plasma perfusate, and generation of complement activation products $\mathrm{C} 3 \mathrm{a}$ and SC5b-9. However, in comparison to normal lungs, hCD59 lungs had reduced deposition of C9 and less histologic evidence of tissue damage. Histologic findings in normal lungs consisted of endothelial cell damage, microvascular thrombosis, intra-alveolar hemorrhage, edema, and neutrophil infiltration, resulting in the rapid dysfunction of the lung. These findings support the concept that the pathophysiologic features of the immunologic injury but not physiologic responses induced by human blood on a pig lung are analogous to that described earlier with a pig heart or kidney with a similar perfusion model. ${ }^{6}$ In these cases, the organ damage is representative of the process of hyperacute rejection that a porcine organ undergoes when transplanted into a primate. ${ }^{15,24,25}$ In one study in which a pig lung was transplanted orthotopically into baboons and cynomolgus monkeys, with the contralateral lung left in place, there was little or no deposition of immunoglobulins and complement in the graft, ${ }^{13}$ a result that may have been due to inadequate perfusion, given the rise in PVR in the xenograft with probable shunting of pulmonary blood flow to the native lung.

Our studies demonstrated that lungs that express hCD59 are strongly protected from injury induced by perfusion with human blood. These lungs survived for at least the 4 hours of observation, in marked contrast to control lungs that survived only an average of 35 minutes. The prolonged survival of hCD59 lungs was associated with decreased PVR and maintenance of pulmonary compliance until termination of the experiment. The differences observed between the transgenic organs and those of outbred controls could potentially be attributed to differences in housing and swine genetics, although less likely than by way of the expression 
of the hCD59 transgene. The pulmonary arterial flows demonstrated are reduced from porcine physiologic levels and may not support adequate cardiac output in an in vivo model of porcine-to-primate pulmonary xenotransplantation. However, this significant protection provided by hCD59 against hyperacute injury of a pig lung by human blood is comparable to the improved function observed with perfused lungs that expressed $\mathrm{hDAF}^{16}$ or hDAF plus hCD59. ${ }^{14}$

Although these experiments do not allow quantitation of the degree of protection, our results highlight the very important role played by the completely assembled membrane attack complex (ie, containing incorporated $C 9$ ) in the pathogenesis of hyperacute rejection in this pig lung-to-human model system. Although additional products of complement activation such as $\mathrm{C} 3 \mathrm{a}$ and C5a may also be important, our results suggest the predominant role of the membrane attack complex in hyperacute xenogeneic lung injury.

Whereas the plasma perfusate of both normal and hCD59 lungs showed strong complement activation when assessed by generation of $\mathrm{C} 3 \mathrm{a}$, in the current series of experiments with whole blood, formation of the soluble complex SC5b-9 was markedly retarded with the hCD59 lungs. In contrast to results with normal lungs, SC5b-9 levels with hCD59 lungs were only slightly elevated after 30 minutes of perfusion but were greatly increased after 4 hours of perfusion. The slower formation of SC5b-9 in the transgenic group is likely due to several factors. The early rise of SC5b-9 levels with normal lungs may be, to a large extent, due to dissociation into the fluid phase of tissue-bound membrane attack complexes that had rapidly bound in the normal lungs but not to the hCD59 lungs. In addition, reduced tissue inflammation in the hCD59 lungs may prevent amplification of $\mathrm{C} 5$ activation as might occur in the control lungs because of activation by other mediators of inflammation. The more rapid blood flow in the hCD59 lungs may impair the fluid phase interaction among late-acting complement proteins, either directly or through the action of complement regulatory proteins.

In conclusion, our studies demonstrate that a porcine lung that expresses hCD59, in comparison to normal controls, undergoes reduced tissue injury when perfused with human blood. The hCD59 lungs had improved function and survival, with diminished tissue deposition of C9 and delayed generation of SC5b-9 in the plasma perfusate. These studies suggest that in pigto-human models of xenotransplantation, hyperacute tissue injury is mediated to a major extent by the assembly of the complete membrane attack complex of complement, C5b-9.
We thank Cathy Devin for her assistance with immunofluorescence tissue preparation and staining, Barbara Benson for her immunoglobulin and complement assay expertise, and Allison Friedenberg, Matthew Lahti, Jason Polovick, Clark Schumacher, and Dany Rodriguez for their technical assistance.

\section{REFERENCES}

1. United Network for Organ Sharing data: http://www.unos.org/ Frame_default.asp?Category=Newsdata.

2. Platt JL, Fischel RJ, Matas AJ, Reif SA, Bolman RM, Bach FJ. Immunopathology of hyperacute xenograft rejection in a swineto-primate model. Transplantation 1991;52:214-20.

3. Auchincloss H Jr. Xenogeneic transplantation. Transplantation 1988;46:1-20.

4. Fodor WL, Williams BL, Matis LA, Madri JA, Rollins SA, Knight JW, et al. Expression of a functional human complement inhibitor in a transgenic pig as a model for the prevention of xenogeneic hyperacute organ rejection. Proc Natl Acad Sci U S A 1994;91:11153-7.

5. Dalmasso AP. The complement system in xenotransplantation. Immunopharmacology 1992;24:149-60.

6. Kroshus TJ, Bolman RM III, Dalmasso AP, Rollins SA, Guilmette ER, Williams BL, et al. Expression of human CD59 in transgenic pig organs enhances organ survival in an ex vivo xenogeneic perfusion model. Transplantation 1996;61:1-9.

7. Waldhausen JA, Webb RC, Spencer FC, Bahnson HT. Study of the canine lung as an oxygenator of human and canine blood in extracorporeal circulation. Surgery 1957;42:726-33.

8. Bryant LR, Eiseman B, Avery M. Studies of the porcine lung as an oxygenator for human blood. J Thorac Cardiovasc Surg 1968; 55:255-63.

9. Pierson RN III, Tew DN, Konig WK, Dunning JJ, White DJG, Wallwork J. Pig lungs are susceptible to hyperacute rejection by human blood in a working ex vivo heart-lung model. Transplant Proc 1994;26:1318.

10. Pierson RN III, Dunning JJ, Konig WK, Tew DN, Braidley PC, Wallwork J, et al. Mechanisms governing the pace and character of pig heart-lung rejection by human blood. Transplant Proc 1994;26:2337.

11. Pierson RN III, Konig WK, Tew DN, Young VK, Dunning JJ, Horsley $\mathrm{J}$, et al. Hyperacute rejection in a pig-to-human transplant model. Transplantation 1997;63:594-603.

12. Macchiarini P, Mazmanian GM, Oriol R. Ex vivo lung model of pig to human hyperacute xenograft rejection. J Thorac Cardiovasc Surg 1997;114:315-25.

13. Kaplon RJ, Platt JL, Kwiatkowski PA, Edwards NM, Xu H, Shah $\mathrm{AS}$, et al. Absence of hyperacute rejection in pig to primate orthotopic pulmonary xenografts. Transplantation 1995;59:410-9.

14. Daggett CW, Yeatman M, Lodge AJ, Chen EP, Van Trigt P, Byrne $\mathrm{GW}$, et al. Swine lungs expressing human complement-regulatory proteins are protected against acute pulmonary dysfunction in a human plasma perfusion. J Thorac Cardiovasc Surg 1997;113: 390-8.

15. Yeatman M, Daggett CW, Parker W, Byrne GW, Logan JS, Platt JL, et al. Complement-mediated pulmonary xenograft injury. Transplantation 1998;65:1084-93.

16. Pierson RN III, Chavez PG, Young VK, Konig WK, White DJG, Wallwork J. Expression of human decay accelerating factor may protect pig lung from hyperacute rejection by human blood. J Heart Lung Transplant 1997;16:231-9. 
17. Platt JL, Turman MA, Noreen HJ, Fischel RJ, Bolman RM, Bach FH. An ELISA assay for xenoreactive natural antibodies. Transplantation 1990;49:1000-1.

18. Kent JF, Fife EH. Precise standardization of reagents for complement fixation. Am J Trop Med 1963;12:103.

19. Laine RO, Esser AF. Identification of the discontinuous epitope in human complement protein $\mathrm{C} 9$ recognized by anti-melitin antibodies. J Immunol 1989;143:553-7.

20. Falk RJ, Dalmasso AP, Kim Y, Tsai CH, Scheinman JI, Gewurz $\mathrm{H}$, et al. Neoantigen of the polymerized ninth component of complement: characterization of a monoclonal antibody and immunohistochemical localization in renal disease. J Clin Invest 1983; 72:560-73.

21. Dalmasso AP, Vercellotti GM, Fischel RJ, Bolman RM, Bach FH, Platt JL. Mechanism of complement activation in the hyperacute rejection of porcine organs transplanted into primate recipients. Am J Pathol 1992;140:1157-66.

22. Kusajima K, Aust JC, Wax SD, Webb WR. Hemodynamic and functional changes in xenogenic, perfused isolated lungs. J Thorac Cardiovasc Surg 1976;72:115-8.

23. Macchiarini P, Oriol R, Azimzadeh A, Montpreville V, Rieben R, Bovin N, et al. Evidence of human non- $\alpha$-galactosyl antibodies involved in the hyperacute rejection of pig lungs and their removal by pig organ perfusion. J Thorac Cardiovasc Surg 1998; 116:831-43.

24. Lau CL, Daggett CW, Yeatman MF, Chai P, Lin SS, Lodge AJ, et al. The role of antibodies in dysfunction of pig-to-baboon pulmonary transplants [abstract]. J Heart Lung Transplant 1999;18:65.

25. Daggett CW, Yeatman M, Lodge AJ, Chen EP, Lin SS, Gullotto $\mathrm{C}$, et al. Total respiratory support from swine lungs in primate recipients. J Thorac Cardiovasc Surg 1998;115:19-27.

\section{Discussion}

Dr Thomas K. Waddell (Toronto, Ontario, Canada). You showed an 8-fold increase in the perfusion time. Having done a bit of work with ex vivo perfusion, I know that you cannot perfuse these models forever. Even perfusing with autologous blood, you are going to damage the lung because of, in some cases, complement activation. Have you studied a control group with autologous perfusion, either as part of this series or in previous experiments?

Dr Kulick. Yes, we did look at autologous perfusion with pig lungs with their own blood. We found that, after 4 to 6 hours of perfusion, oxygenation would decrease, pulmonary edema would form, and this limited the validity of this model for hyperacute rejection studies only.

Dr Valerie W. Rusch (New York, NY). Tell us where you are going next.

Dr Kulick. The CD59 transgenic has been improved on. There are double transgenics now for both decay-accelerating factor and hCD59. At our institution, we now have access to transgenic swine that are double transgenic for the h-transferase gene, which downregulates endogenous expression of the $\alpha$-gal epitope in addition to hCD59, and we hope to start some studies with those double transgenic organs soon.

Dr Mark K. Ferguson (Chicago, Ill). Is there some variability in the expression of hCD59 in these transgenic animals?

Dr Kulick. Interestingly, there is. All of the animals that we used were heterozygous. Homozygous expression of the hCD59 transgene has not been shown to increase the tissue expression of hCD59. We obtained one animal that was an hCD59 low expresser. We tested the lungs on our perfusion circuit, and it behaved much as a control lung did. This was not included in our results presented today.

Dr Ferguson. At the conclusion of the 4-hour perfusion period, what does the lung look like?

Dr Kulick. The lung does not look like a healthy lung, but it does not look that bad. The control lungs are firm and consolidated to the touch, and they have confluent hemorrhagic petechiae on their surface. The transgenic lungs have scattered areas of petechial hemorrhage, but they are soft. Their ability to oxygenate is good, but the flows may not be sufficient to support transplantation into an in vivo primate model.

\section{Timely}

The Journal of Thoracic and Cardiovascular Surgery delivers the information you need now. Articles usually appear within four months of acceptance. 